\title{
Factors Related to Functional Capacity and Quality of Life for Elderly People in a Middle-Sized City of São Paulo, Brazil
}

\author{
Giovana Fumes-Ghantous ${ }^{1}$, José Eduardo Corrente², \\ Ana Flavia Giacondino Soligo Lezcano Tatis ${ }^{3}$
}

\footnotetext{
${ }^{1}$ Basic Sciences Department, Faculty of Animal Science and Food Engineering, University of São Paulo, Pirassununga, Brazil ${ }^{2}$ Research Support Office, Botucatu Medicine School, University of São Paulo State, Botucatu, Brazil

${ }^{3}$ Faculty of Animal Science and Food Engineering, University of São Paulo, Pirassununga, Brazil Email: ^gifumesbtu@usp.br
}

How to cite this paper: Fumes-Ghantous, G., Corrente, J.E. and Tatis, A.F.G.S.L. (2020) Factors Related to Functional Capacity and Quality of Life for Elderly People in a Middle-Sized City of São Paulo, Brazil. Health, 12, 1562-1574.

https://doi.org/10.4236/health.2020.1212113

Received: September 25, 2020

Accepted: December 18, 2020

Published: December 21, 2020

Copyright $\odot 2020$ by author(s) and Scientific Research Publishing Inc. This work is licensed under the Creative Commons Attribution International License (CC BY 4.0).

http://creativecommons.org/licenses/by/4.0/

\begin{abstract}
Introduction: It is a fact that the elderly population has been increasing all around the world and also in Brazil. This has been a challenge for governments and managers in the development of public policies to promote healthy and quality aging. And one of the conditions for healthy aging is to assess the functional capacity and quality of life of elderly people. Objective: The aim of the present study was to evaluate the factors that influence the loss of functional capacity and the worsening of the quality of life of a representative sample of elderly people from a medium-sized city in the inner of São Paulo State, Brazil. Methodology: Questionnaires about activities of daily living (ADL), instrumental activities of daily living (IADL), Flanagan quality of life scale (FQOLS), sociodemographic and morbidities aspects were applied to the elderly people. In order to assess associated factors to functional capacity and quality of life, chi-square tests and logistic regression models were fitted including variables: gender, age group, marital status, income, education level, body mass index, abdominal circumference and some morbidities reported by the elderly people. The level of significance adopted for the statistical tests was 5\%. Results: Elderly with age over 75 years old and not married had more risk to be dependent on ADL, while elderly with more than 75 years old, not married, income below one minimal wage, cardiovascular disease and be diabetic had more risk to be dependent by IADL. Already, people with excess of weight had smallest risk to be dependent by IADL, paradoxically. The elderly not married and with an income below a minimum wage had the worst quality of life. Conclusions: Population aging in Brazil is an evident factor, so it is hoped that this study will contribute to the greatest diligence on
\end{abstract}


the issues of the elderly and related social problems.

\section{Keywords}

Functional Capacity, Life Quality, Odds Ratio, Risk Factors

\section{Introduction}

The world elderly population has been a significant increase in recent decades, especially in Latin American countries [1]. For the World Health Organization (WHO), the elderly are the person aged 60 or over in developing countries. In Brazil, according to the Brazilian Institute of Geography and Statistics Foundation (IBGE), the number of elderly people has already exceeded 28 million individuals, which may double in the next decades. The federal law no. 10,741/2003 establishes the Senior Citizen's Statute, which mainly regulates the right of elderly people to protection measures, care policies and access to justice. In addition, it is important for managers and society to develop actions to promote active life in this age group [2] [3].

Due to the rapid growth of elderly people in Brazil, concerns about the quality of life and functional capacity are essential to define interventions and to monitor the clinical condition of these elderly people [4].

Functional capacity is defined as the individual's ability to take care of himself/herself, living independently [4]. The assessment of functional capacity can be done considering aspects related to activities of daily living (ADL) and instrumental activities of daily living (IADL) [4]. The ADL refer to self-care, such as bathing, dressing, eating, being continent and they are obtained by the Katz Index [5]. The IADL are those related to more complex actions, such as socialization, like to do shopping, using the phone, driving and taking public transportation [6].

Quality of life is a more subjective and multidimensional concept, related to self-esteem, personal well-being, functional capacity, socioeconomic level, emotional state, social interaction, intellectual activity, self-care, family support, the state of health himself/herself, cultural and ethical values and religiosity, lifestyle, satisfaction with job and the environment in which they live [7] [8]. Nowadays, there are several instruments to assess the quality of life in a population, including the Flanagan Quality of Life Scale (FQOLS), which takes these aspects into account.

The FQOLS was developed in the United States during the 1970's to measure the quality of life across a random sampling of 3000 American adults using an interview technique [9]. The original scale was translated into Portuguese although the authors did not make any reference to the reliability of the version [10].

Thus, this study aimed to assess the factors that influence functional capacity 
and quality of life in the elderly living in a medium-sized city in the inner of the São Paulo State, Brazil.

\section{Methodology}

The data used in the present study came from an epidemiological study carried out in the municipality of Botucatu, in the interior of the state of São Paulo, Brazil, which aimed to assess the quality of life of the elderly, obtained in 2003. For the initial dataset, a systematic random sample of households in the municipality was made, covering a quarter of households in each census sector. All residents were cataloged. In a second stage, within each census sector, residents were randomly sampled over the age of 60 years [7].

The minimum sample size was calculated using the formula:

$$
n=z_{\alpha / 2}^{2} p(1-p) / \varepsilon^{2},
$$

in which $n$ represents the minimum number of elderly people; $z=1.96$ (value for a bilateral confidence interval of $95 \%$ from a standard normal distribution); $\varepsilon$ is the sampling error, set in 0.05 and $p$ is a prevalence of a relevant feature. In this case, as the prevalence of quality of life for elderly people was unknown, it was considered $\mathrm{p}=0.5$. Then, it was obtained 384 vanishing the heterogeneity factor associated with the cluster sample design.

For the present study, the elderly people were contacted in 2010 for a new interview. Those who did not agree to participate or who had already passed away were replaced by a new drawing in the database.

At the time, a sociodemographic and morbidity questionnaire was applied plus the Activities of Daily Living scale (ADL), the Instrumental Activities of Daily Living scale (IADL) and the Flanagan Quality of Life Scale (FQOLS). The sample was collected in 2011.

The used scale for ADL contains six questions considering the answers "yes" or "no". One point was awarded for each affirmative answer. More than four points was classified as independent, while those with 4 or less points were classified as dependent [5].

The scale for IADL has nine questions whose answers are: "can't do it", "can do it with help" and "can do it without help". For the answer "can't do it", 1 point was awarded; "can do it with help", 2 points and "do it without help", 3 points. The sum of the points provides the score and the classification was: independent for more than 17 points and dependent for 17 points or less [6].

On the other hand, the FQOLS contains fifteen questions in which each question is evaluated according to a 7-point Likert scale, ranging from 1 ("very dissatisfied") to 7 ("very satisfied"). The final score is calculated by adding of the value in each question, ranging from 15 to 105 points. As there is no cut-off point for assessing quality of life, the median value was used in this study, classifying values above the median as good quality of life and below the median as poor quality of life.

The demographic data collected were: gender (male/female), age group (up to 
75 years old/over 75 years old), marital status (married/not married), income (up to one minimum wage/over one minimum wage of US\$33,000 at that time), schooling (up to elementary school/over elementary school), still working (yes/no), retired (yes/no), number of people in the house (1, 2, 3 and $\geq 4$ ), Body Mass In$\operatorname{dex}(\mathrm{BMI})$ (eutrophic (IMC $\leq 28)$ /overweight (IMC $>28)$ ), abdominal circumference (normal/altered) and some referred morbidities as hypertension (yes/no), diabetes mellitus (yes/no), cardiovascular disease (yes/no), cholesterol (yes/no), and osteoporosis (yes/no).

The association between functional capacity and quality of life with the other variables was obtained using the chi-square test. To evaluate the risk factors for functional dependence and worse quality of life, two logistic regression models were proposed: one using the stepwise procedure to select explanatory variables and a second, considering the variables that showed significant associations in the chi-square test. Pearson correlations among FQOLS, ADL and IADL were calculated. The significance level of $5 \%$ was set for all tests. The analyzes were made using the $\mathrm{R}$ version 3.6.2 and SAS for windows version 9.4 programs.

The Ethics Committee of the Medical School of São Paulo State University Botucatu, São Paulo, Brazil approved this research, protocol number 3111/2009.

\section{Results}

According to the calculated sample, 368 elderly form the municipality were interviewed, in which $38(10 \%)$ did not complete the research protocol to evaluate the functional capacity and quality of life. The mean age of the elderly was $72.1 \pm$ 7.3 years old, ranging from 60 to 92 years old. The average age for men was 71.5 \pm 7.3 years old and for women $72.4 \pm 7.3(\mathrm{p}$-value $=0.25)$. Table 1 presents the sample description.

Table 2 presents the association among classification of ADL and the other variables.

According to Table 2, age group, marital status and income were significantly associated to the classification of functional capacity evaluated by the ADL ( $\mathrm{p}<$ 0.05).

Associations among classification of IADL and the other variables are presented in Table 3.

According to Table 3, age group, marital status, income, BMI and cardiovascular disease presented significant associations with the classification of IADL.

Evaluating the FQOLS, the mean final score was $84.72 \pm 10.34$, ranging from 44 to 105 points. The median value was 85.5 and, considering it as the cut-off for quality of life, Table 4 presents the associations with other variables.

Gender, age group, marital status, income, schooling and hypertension presented significant associations with the classification of quality of life by the FQOLS (Table 4).

Considering now being dependent for ADL as much as IADL as response variable, multiple logistic regression models were fitted taking into account the 
Table 1. Characteristics of the elderly sample. Botucatu, São Paulo, Brazil, 2011.

\begin{tabular}{|c|c|c|c|}
\hline Variables & Categories & $\mathbf{N}$ & $\%$ \\
\hline \multirow[t]{2}{*}{ Gender } & Male & 136 & 36.96 \\
\hline & Female & 232 & 63.04 \\
\hline \multirow[t]{2}{*}{ Age group } & Up to 75 years old & 251 & 68.21 \\
\hline & Over 75 years old & 117 & 31.79 \\
\hline \multirow[t]{2}{*}{ Marital status } & Married & 212 & 57.61 \\
\hline & Not married & 156 & 42.39 \\
\hline \multirow[t]{2}{*}{ Schooling } & Up to Elementary School & 284 & 77.17 \\
\hline & Over Elementary School & 84 & 22.83 \\
\hline \multirow[t]{2}{*}{ Still working } & Yes & 39 & 10.60 \\
\hline & No & 329 & 89.40 \\
\hline \multirow[t]{2}{*}{ Retired } & Yes & 320 & 86.96 \\
\hline & No & 48 & 13.04 \\
\hline \multirow{4}{*}{$\begin{array}{l}\text { Number of people living } \\
\text { in the House }\end{array}$} & 1 & 59 & 16.03 \\
\hline & 2 & 146 & 39.67 \\
\hline & 3 & 83 & 22.55 \\
\hline & $\geq 4$ & 80 & 21.74 \\
\hline Body Mass & Eutrophic $(\leq 28)$ & 200 & 54.35 \\
\hline Index (BMI) & Overweight (> 28) & 168 & 45.65 \\
\hline Abdominal & Normal & 134 & 36.41 \\
\hline circumference & Altered & 234 & 63.59 \\
\hline \multirow[t]{2}{*}{ Hypertension } & Yes & 206 & 55.98 \\
\hline & No & 162 & 44.02 \\
\hline \multirow[t]{2}{*}{ Diabetes mellitus } & Yes & 105 & 28.53 \\
\hline & No & 263 & 71.47 \\
\hline \multirow[t]{2}{*}{ Cardiovascular disease } & Yes & 27 & 7.34 \\
\hline & No & 341 & 92.66 \\
\hline \multirow[t]{2}{*}{ Cholesterol } & Yes & 56 & 15.22 \\
\hline & No & 312 & 84.78 \\
\hline \multirow[t]{2}{*}{ Osteoporosis } & Yes & 33 & 8.97 \\
\hline & No & 335 & 91.03 \\
\hline \multirow[t]{2}{*}{$\mathrm{ADL}$} & Independent & 311 & 94.24 \\
\hline & Dependent & 19 & 5.76 \\
\hline \multirow[t]{2}{*}{ IADL } & Independent & 304 & 92.12 \\
\hline & Dependent & 26 & 7.88 \\
\hline
\end{tabular}

ADL—activities of daily living; IADL—instrumental activities of daily living. 
Table 2. Association among socio-demographic and morbidities data with the classification of ADL.

\begin{tabular}{|c|c|c|c|c|}
\hline \multirow[b]{2}{*}{ Variables } & \multirow[b]{2}{*}{ Categories } & \multicolumn{2}{|c|}{ ADL Classification } & \multirow[b]{2}{*}{ p-value } \\
\hline & & $\begin{array}{l}\text { Dependent } \\
\text { n (\%) }\end{array}$ & $\begin{array}{c}\text { Independent } \\
\mathrm{n}(\%)\end{array}$ & \\
\hline \multirow[t]{2}{*}{ Gender } & Male & $4(21.05)$ & $121(38.91)$ & 0.1194 \\
\hline & Female & $15(78.95)$ & $190(61.09)$ & \\
\hline \multirow[t]{2}{*}{ Age group } & Up to 75 years old & $8(42.11)$ & $222(71.38)$ & 0.0070 \\
\hline & Over 75 years old & $11(57.89)$ & $89(28.62)$ & \\
\hline \multirow[t]{2}{*}{ Marital status } & Married & $4(21.05)$ & $188(60.45)$ & 0.0007 \\
\hline & Not married & $15(78.95)$ & $123(39.55)$ & \\
\hline \multirow[t]{2}{*}{ Income } & Up to one minimum wage & $9(64.29)$ & $99(36.13)$ & 0.0338 \\
\hline & Over one minimum wage & $5(35.71)$ & $175(63.87)$ & \\
\hline \multirow[t]{2}{*}{ Schooling } & Up to Elementary School & $17(89.47)$ & $237(76.21)$ & 0.2634 \\
\hline & Over Elementary School & $2(10.53)$ & $74(23.79)$ & \\
\hline Body Mass & Eutrophic ( $\leq 28)$ & $13(68.42)$ & $170(54.66)$ & 0.2414 \\
\hline Index & Overweight (>28) & $6(31.58)$ & $141(45.34)$ & \\
\hline Abdominal & Normal & $5(26.32)$ & $118(37.94)$ & 0.3089 \\
\hline circumference & Altered & $14(73.68)$ & $193(62.06)$ & \\
\hline Diabetes & Yes & $7(36.84)$ & $86(27.65)$ & 0.3874 \\
\hline mellitus & No & $12(63.16)$ & $225(72.35)$ & \\
\hline \multirow[t]{2}{*}{ Hypertension } & Yes & $14(73.68)$ & $168(54.02)$ & 0.0943 \\
\hline & No & $5(26.32)$ & $143(45.98)$ & \\
\hline Cardiovascular & Yes & $3(15.79)$ & $22(7.07)$ & 0.1656 \\
\hline disease & No & $16(84.21)$ & $289(92.93)$ & \\
\hline
\end{tabular}

Table 3. Association among socio-demographic variables, morbidities and the classification of IADL.

\begin{tabular}{|c|c|c|c|c|}
\hline \multirow[b]{2}{*}{ Variables } & \multirow[b]{2}{*}{ Categories } & \multicolumn{2}{|c|}{ IADL Classification } & \multirow[b]{2}{*}{$\mathrm{p}$-value } \\
\hline & & $\begin{array}{l}\text { Dependent } \\
\text { n (\%) }\end{array}$ & $\begin{array}{c}\text { Independent } \\
\mathrm{n}(\%)\end{array}$ & \\
\hline \multirow[t]{2}{*}{ Gender } & Male & $9(34.62)$ & $116(38.16)$ & 0.7208 \\
\hline & Female & $17(65.38)$ & $188(61.84)$ & \\
\hline \multirow[t]{2}{*}{ Age group } & Up to 75 years old & $10(38.46)$ & $220(72.37)$ & 0.0003 \\
\hline & Over 75 years old & $16(61.54)$ & $84(27.63)$ & \\
\hline \multirow[t]{2}{*}{ Marital status } & Married & $9(34.62)$ & $183(60.20)$ & 0.0111 \\
\hline & Not married & $17(65.38)$ & $121(39.80)$ & \\
\hline \multirow[t]{2}{*}{ Income } & Up to one minimum wage & $14(66.67)$ & $94(35.21)$ & 0.0041 \\
\hline & Over one minimum wage & $7(33.33)$ & $173(64.79)$ & \\
\hline
\end{tabular}




\begin{tabular}{ccccc} 
Continued & & & & \\
\hline Schooling & Up to Elementary School & $24(92.31)$ & $230(75.66)$ & 0.0529 \\
& Over Elementary School & $2(7.69)$ & $74(24.34)$ & \\
Body Mass & Eutrophic $(\leq 28)$ & $21(80.77)$ & $162(53.29)$ & 0.0068 \\
Index & Overweight $(>28)$ & $5(19.23)$ & $142(46.71)$ & \\
Abdominal & Normal & $13(50.00)$ & $110(36.18)$ & 0.1132 \\
circumference & Altered & $13(50.00)$ & $194(63.82)$ & \\
$\begin{array}{c}\text { Diabetes } \\
\text { mellitus }\end{array}$ & Yes & $11(42.31)$ & $82(26.97)$ & 0.0953 \\
Hypertension & No & $15(57.69)$ & $222(73.03)$ & \\
& Yes & $15(57.69)$ & $167(54.93)$ & 0.7861 \\
Cardiovascular & No & $11(42.31)$ & $137(45.07)$ & \\
disease & Yes & $7(26.92)$ & $18(5.92)$ & 0.0001 \\
\hline
\end{tabular}

Table 4. Association among socio-demographic variables, morbidities and the classification of quality of life.

\begin{tabular}{|c|c|c|c|c|}
\hline \multirow[b]{2}{*}{ Variables } & \multirow[b]{2}{*}{ Categories } & \multicolumn{2}{|c|}{ QOLS Classification } & \multirow[b]{2}{*}{ p-value } \\
\hline & & $\begin{array}{l}\text { Good QOL } \\
\text { n (\%) }\end{array}$ & $\begin{array}{c}\text { Poor QOL } \\
\text { n (\%) }\end{array}$ & \\
\hline \multirow[t]{2}{*}{ Gender } & Male & $73(43.71)$ & $54(32.34)$ & 0.0322 \\
\hline & Female & $94(56.29)$ & $113(67.66)$ & \\
\hline \multirow[t]{2}{*}{ Age group } & Up to 75 years old & $124(74.25)$ & $105(62.87)$ & 0.0251 \\
\hline & Over 75 years old & $43(25.75)$ & $62(37.13)$ & \\
\hline \multirow[t]{2}{*}{ Marital status } & Married & $122(73.05)$ & $72(43.11)$ & $<0.0001$ \\
\hline & Not married & $45(26.95)$ & $95(56.89)$ & \\
\hline \multirow[t]{2}{*}{ Income } & Up to one minimum wage & $38(26.95)$ & $68(44.74)$ & 0.0015 \\
\hline & Over one minimum wage & $103(73.05)$ & $84(55.26)$ & \\
\hline \multirow[t]{2}{*}{ Schooling } & Up to Elementary School & $118(70.66)$ & $135(80.84)$ & 0.0300 \\
\hline & Over Elementary School & $49(29.34)$ & $32(19.16)$ & \\
\hline \multirow[t]{2}{*}{ Body Mass Index } & Eutrophic $(\leq 28)$ & $96(57.49)$ & $90(53.89)$ & 0.5087 \\
\hline & Overweight (>28) & $71(42.51)$ & $77(46.11)$ & \\
\hline Abdominal & Normal & $107(37.02)$ & $17(37.78)$ & 0.9225 \\
\hline circumference & Altered & $182(62.98)$ & $28(62.22)$ & \\
\hline \multirow[t]{2}{*}{ Diabetes mellitus } & Yes & $41(24.55)$ & $54(32.34)$ & 0.1149 \\
\hline & No & $126(75.45)$ & $113(67.66)$ & \\
\hline \multirow[t]{2}{*}{ Hypertension } & Yes & $81(48.50)$ & $104(62.28)$ & 0.0113 \\
\hline & No & $86(51.50)$ & $63(37.72)$ & \\
\hline \multirow{2}{*}{$\begin{array}{l}\text { Cardiovascular } \\
\text { diseases }\end{array}$} & Yes & $8(4.79)$ & $16(9.48)$ & 0.0901 \\
\hline & No & $159(95.21)$ & $151(90.42)$ & \\
\hline
\end{tabular}


others variables as explanatory for two approaches: using the stepwise selection method and including the variables significantly associated for the chi-square test. The results can be seen in Table 5 and Table 6.

Table 5 shows that the logistic model fitted considering to be dependent by the ADL, age group and marital status were risk factors using stepwise method. Including all significant variables, it can be observed that income appears as a confounding factor.

Table 5. Multiple logistic regression for be dependent according to ADL.

\begin{tabular}{ccc}
\hline & \multicolumn{2}{c}{ Model 1 (Stepwise) Model 2 (Chi-square) } \\
\cline { 2 - 3 } Parameters & OR CI (95\%) & OR CI (95\%) \\
Age group & $2.80(1.07 ; 7.33)$ & $2.34(0.76 ; 7.22)$ \\
Over 75 years old & 1.00 & 1.00 \\
Up to 75 years old & & $3.25(0.97 ; 10.94)$ \\
Marital status & $\mathbf{5 . 0 0 ( 1 . 6 0 ; 1 5 . 5 9 )}$ & 1.00 \\
Not married & $\mathbf{1 . 0 0}$ & $3.02(0.96 ; 9.54)$ \\
Married & - & 1.00 \\
Income & - & \\
Up to one minimum wage & & \\
Over one minimum wage & & \\
\hline
\end{tabular}

Table 6. Multiple logistic regression for be dependent according to IADL.

\begin{tabular}{|c|c|c|}
\hline \multirow{2}{*}{ Parameters } & \multicolumn{2}{|c|}{ Model 1 (Stepwise) Model 2 ( Chi-square) } \\
\hline & OR CI (95\%) & OR CI (95\%) \\
\hline \multicolumn{3}{|l|}{ Age group } \\
\hline Over 75 years old & $3.74(1.31 ; 10.67)$ & $3.40(1.23 ; 9.39)$ \\
\hline Up to 75 years old & 1.00 & 1.00 \\
\hline \multicolumn{3}{|l|}{ Marital status } \\
\hline Not married & $2.91(1.00 ; 8.55)$ & $2.55(0.90 ; 7.21)$ \\
\hline Married & 1.00 & 1.00 \\
\hline \multicolumn{3}{|l|}{ Income } \\
\hline Up to one minimum wage & $3.99(1.36 ; 11.71)$ & $3.76(1.32 ; 10.72)$ \\
\hline Over one minimum wage & 1.00 & 1.00 \\
\hline \multicolumn{3}{|l|}{ Body Mass Index } \\
\hline Overweight & $0.15(0.04 ; 0.57)$ & $0.18(0.05 ; 0.66)$ \\
\hline Normal & 1.00 & 1.00 \\
\hline \multicolumn{3}{|l|}{ Cardiovascular disease } \\
\hline Yes & $6.99(1.96 ; 24.89)$ & $5.44(1.62 ; 18.24)$ \\
\hline No & 1.00 & 1.00 \\
\hline \multicolumn{3}{|l|}{ Diabetes mellitus } \\
\hline Yes & $4.07(1.37 ; 12.07)$ & - \\
\hline No & 1.00 & - \\
\hline
\end{tabular}


Table 7. Multiple logistic regression for the classification of quality of life according to FQOLS.

\begin{tabular}{|c|c|c|}
\hline \multirow{2}{*}{ Parameters } & \multicolumn{2}{|c|}{ Model 1 (Stepwise) Model 2 ( Chi-square) } \\
\hline & OR CI $(95 \%)$ & OR CI (95\%) \\
\hline \multicolumn{3}{|l|}{ Gender } \\
\hline Male & - & $1.17(0.67 ; 2.07)$ \\
\hline Female & - & 1.00 \\
\hline \multicolumn{3}{|l|}{ Age group } \\
\hline Over 75 years old & - & $1.58(0.91 ; 2.73)$ \\
\hline Up to 75 years old & - & 1.00 \\
\hline \multicolumn{3}{|l|}{ Marital status } \\
\hline Not married & $3.27(1.99 ; 5.38)$ & $3.17(1.81 ; 5.56)$ \\
\hline Married & 1.00 & 1.00 \\
\hline \multicolumn{3}{|l|}{ Income } \\
\hline Up to one minimum wage & $2.40(1.44 ; 4.02)$ & $2.18(1.23 ; 3.85)$ \\
\hline Over one minimum wage & 1.00 & 1.00 \\
\hline \multicolumn{3}{|l|}{ Schooling } \\
\hline Up to Elementary School & - & $1.19(0.63 ; 2.24)$ \\
\hline Over Elementary School & - & 1.00 \\
\hline \multicolumn{3}{|l|}{ Hypertension } \\
\hline Yes & - & $1.59(0.96 ; 2.62)$ \\
\hline No & - & 1.00 \\
\hline
\end{tabular}

For the functional dependency evaluated by IADL (Table 6), the diabetes was included into the model as risk factor, whereas in the chi-square tests it was not obtained a significant association. Therefore, the inclusion of diabetes into the model appears as a moderate factor for a functional dependency in this case.

Table 7 presents the logistic model for the classification of quality of life according to FQOLS.

Marital status and income were risk factor for a poor quality of life according to the stepwise logistic model, providing the same result when including all significant variables by the chi-square test. Then, gender, age group, schooling and hypertension are not confounder variables.

The Pearson correlations between FQOLS and ADL scores $(r=0.23, \mathrm{p}<$ $0.0001)$ and IADL $(r=0.29, p<0.0001)$ were positive and significant, in spite of being quite low.

\section{Discussion}

The present study evaluated 368 elderly people in a medium-sized city in the São Paulo State, Brazil, between the years 2010 and 2011, in which 38 elderly people did not fully complete the protocol established to assess functional capacity and quality of life. Although the sample was drawn to be representative based on a database of the city's elderly population, it was observed that the percentage of 
women was bigger $(63.0 \%)$ than men with an average age of 72.1 years, ranging from 60 to 96 years.

It was found that $5.8 \%$ of the elderly were classified as dependent for ADL and $7.9 \%$ for IADL, with no association with sex. Age, marital status and income were associated with the ADL classification. Already, age group, marital status, income, schooling, BMI and cardiovascular diseases were associated with dependence for IADL. These results are similar to the study with elderly people assisted in the Family Health Strategy (FHS) of Montes Claros, Minas Gerais, Brazil [11] and the other one that evaluate elderly people from a three family health groups in the municipality of Recife, Pernambuco, Brazil [12]. A study conducted in Juiz de Fora, Minas Gerais, Brazil, on the other hand, found no significant associations between demographic variables and dependence for ADL [13]. The population-based study "Steps to Active Aging" (PEA study/Brazil) also obtained results similar to the present study, which also evaluated the level of physical activity and the perception of health of the elderly [14].

Fitting the multiple logistic model for the factors associated with functional dependence for the elderly regarding ADL, only age over 75 years old and being not married were obtained as risk factors considering the stepwise method. Income appears as a confounding factor in this case, may be because not all the elderly people declare it at the time of the interview, reducing the sample size and favoring a loss of significance for the other factors. A study with long-lived elderly people living in the community also did not find a significant association with income in the multiple logistic models [15].

Considering now the dependence assessed by the IADL, a significant association of the classification was obtained with age, marital status, income, education, BMI and cardiovascular diseases, results that agree with the "Steps of Active Aging" (PEA-Brasil study) [14], as well as a study of the elderly in Montes Claros, Minas Gerais, Brazil [11] and the study of the elderly in the city of São Paulo, São Paulo, Brazil [16]. In multiple logistic models, being over 75 years old, not married, having an income up to a minimum wage and having cardiovascular disease and diabetes were risk factors for dependence for IADL. People who perceive up to a minimum wage suffer greater exposure to risk factors and have less access to health services than those who earn more, and therefore, this may have caused this difference in relation to their autonomy when performing self-care tasks [17]. For the study conducted in Juiz de Fora, Minas Gerais, Brazil, only a significant association was found for the age group [13]. An interesting aspect was that the elderly being overweight was a protective factor for dependence in this case, indicating which refers to the obesity paradox for the elderly, who says that being overweight can, in some aspects, be beneficial for the individual.

Additionally, the fact that the individual is female or male did not impact his autonomy to develop care activities at home (ADL) and outside the home (IADL). Studies suggest that younger men are more independent in relation to 
women, who are forced to do housework. However, in old age there is a loss of power for men, reflecting on their functional capacity, which occurs in the opposite way for women, who, over the years, apparently gain some freedom and independence [18].

Evaluating the quality of life for the elderly according to the FQOLS, associations were obtained with gender, age group, marital status, income, schooling and hypertension, but in the multiple logistic models, only being not married and having an income below one minimum wage were risk factors for a worst quality of life. A study developed for the elderly in the cities of Mogi das Cruzes and São Bernardo do Campo, São Paulo, Brazil, showed that the absence of diseases associated positively with the quality of life assessed by WHOQOL-Brief in the first city, in addition to complete higher education, advanced age, absence of diseases and having residence in São Caetano do Sul, Brazil [19]. Additionally, it is believed that the support associated with marital relationships, may contribute for a healthier lifestyle [18]. The study conducted in social groups in the city of Campina Grande, Paraíba, Brazil, found a significant correlation between the quality of life score measured by WHOQOL-OLD and AIVD, but without significant correlation with ADL [20]. In the present study, a significant and positive correlation was found among ADL, IADL and FQOLS.

Some limitations of the present study may be the fact that the sample contains some representation bias regarding gender. Another point that may be sensitive in the present study is the question of income, in which many elderly people are uncomfortable when referring to the level of income and, sometimes, even afraid to mention the true value, foreseeing some possible loss of the benefit they receive. Despite of this, income was a determining factor in the three aspects assessed in the present study. Even so, the results obtained for functional capacity and quality of life proved to be robust and with a strong association with the evaluated outcomes, including the observed losses. It is also noted that, even though the data is from the year 2011, the reality regarding the elderly in matters of functionality and quality of life still remain unchanged when compared with recent studies, revealing that little has been done for healthy aging in this age group.

\section{Conclusions}

The results found in this study, we can conclude that the age group, marital status, income, nutritional status, cardiovascular disease and diabetes mellitus were factors that influenced elderly people in this population according to daily and instrumental activities of daily living. Additionally, marital status and income were determining factors for assessing the quality of life of the elderly.

The results found highlight problematic points that persist in this age group of the Brazilian population, such as low wages and morbidities and; how these factors have negatively influenced functional capacity and quality of life. The aging of the population in Brazil is a fact, therefore, it is expected that the present 
study contributes to greatest diligence to the issues of the elderly and related social problems, in the sense of encouraging public policies in welcoming the elderly.

\section{Acknowledgements}

The authors would like to thank São Paulo Research Foundation (FAPESPProcess no. 2020/03228-6 and Process no. 2019/02231-6) for the financial support.

\section{Conflicts of Interest}

The authors declare no conflicts of interest regarding the publication of this paper.

\section{References}

[1] World Health Organization (2015) World Report on Ageing and Health. World Health Organization, Geneva.

[2] Tuckett, A.G., Banchoff, A.W., Winter, S.J. and King, A.C. (2018) The Built Environment and Older Adults: A Literature Review and an Applied Approach to Engaging Older Adults in Built Environment Improvements for Health. International Journal of Older People Nursing, 13, Article ID: e12171. https://doi.org/10.1111/opn.12171

[3] Clarke, P. and Nieuwenhuijsen, E.R. (2009) Environments for Healthy Ageing: A Critical Review. Maturitas, 64, 14-19. https://doi.org/10.1016/j.maturitas.2009.07.011

[4] Pinto, A.H., Lange, C., Pastore, C.A., Llano, P.M.P., Castro, D.P. and Santos, F. (2016) Functional Capacity to Perform Activities of Daily Living among Older Persons Living in Rural Areas Registered in the Family Health Strategy. Ciência \& Saúde Coletiva, 21, 3545-3555. https://doi.org/10.1590/1413-812320152111.22182015

[5] Katz, S., Ford, A.B., Moskowitz, R.W., Jackson, B.A. and Jaffe, M.W. (1963) Studies of Illness in the Aged. The Index of ADL: A Standardized Measure of Biological and Psychosocial Function. JAMA, 185, 914-919. https://doi.org/10.1001/jama.1963.03060120024016

[6] Lawton, M.P. and Brody, E.M. (1969) Assessment of Older People: Self-Maintaining and Instrumental Activities of Daily Living. Gerontologist, 9, 179-186. https://doi.org/10.1093/geront/9.3_Part_1.179

[7] Vecchia, R.D., Ruiz, T., Bocchi, S.C.M. and Corrente, J.E. (2005) Quality of Life in the Elderly: A Subjective Concept. Brazilian Epidemiology Journal, 8, 246-252. https://doi.org/10.1590/S1415-790X2005000300006

[8] Tavares, D.M.S., Bolina, A.F., Dias, D.A., Ferreira, P.C.S. and Haas, V.J. (2014) Quality of Life of Elderly. Comparison between Urban and Rural Areas. Investacióny Educaciónen Enfermería, 32, 401-413.

[9] Flanagan, J.C. (1982) Measurement of the Quality of Life: Current State of the Art. Archives of Physical Medicine and Rehabilitation, 63, 56-59.

[10] Hashimoto, H., Guedes, S.L. and Pereira, V.C. (1996) The Ostomy and Quality of Life: An Approach Based on the Dimensions of Quality of Life Proposed by Flanagan. Revista Brasileira de Colo-Proctologia, 16, 74. 
[11] Barbosa, B.R., Almeida, J.M., Barbosa, M.R. and Rossi-Barbosa, L.A.R. (2014) Evaluation of the Functional Capacity of the Elderly and Factors Associated with Disability. Ciência \& Saúde Coletiva, 19, 3317-3325. https://doi.org/10.1590/1413-81232014198.06322013

[12] Araujo, G.K.N., Souto, R.Q., Pottes, F.A., Sousa, R.C.R., Ceballos, A.G.C., Santos, R.C., Lyra, E.V.V. and Nogueira, R.T.A. (2019) Functional Capability and Associated Factors in the Elderly Living in the Community. Acta Paulista de Enfermagem, 32, 312-318. https://doi.org/10.1590/1982-0194201900043

[13] Cruz, D.T., Leite, I.G., Barbosa, M.B. and Leite, I.C.G. (2016) Disability Prevalence Functional and Sociodemographic Factors Associated in out of Judge of Elderly, MG. Revista Kairós de Gerontologia, 19, 9-28.

https://doi.org/10.23925/2176-901X.2016v19iEspecial22p09-28

[14] Virtuoso-Júnior, J.S., Tribess, S., Menezes, A.S., Meneguci, J. and Sasaki, J.E. (2016) Factors Associated with Functional Disability in Brazilian Older Adults. Revista Andaluza de Medicina del Deporte. https://doi.org/10.1016/j.ramd.2016.05.003

[15] Brito, T.A., Fernandes, M.H., Coqueiro, R.S., Jesus, C.S. and Freitas, R. (2014) Functional Capacity and Associated Factors among Longevous Senior Individuals Living in Community: A Population Study in Northeastern Brazil. Fisioterapia e Pesquisa, 21, 308-313.

[16] Alves, L.C., Leimann, B.C.Q., Vasconcelos, M.E.L., Carvalho, M.S., Vasconcelos, A.G.G., Fonseca, T.C.O., Lebrão, M.L. and Laurenti, R. (2007) The Effect of Chronic Diseases on Functional Status of the Elderly Living in the City of São Paulo, Brazil. Reports in Public Health, 23, 1924-1930. https://doi.org/10.1590/S0102-311X2007000800019

[17] Pereira, I.F.S. (2019) Life Expectancy Free of Lifestyle-Related Risk Factors in the Brazilian Population. Ph.D.Thesis, Rio Grande do Norte Federal University, Natal.

[18] Figueiredo, M.L.F., Tyrrel, M.A.R., Carvalho, C.M.R.G., Luz, M.H.B.A., Amorim, F.C.M. and Loiola, N.L.A. (2007) Gender Differences in the Oldness. Revista Brasileira de Enfermagem, 60, 422-427. https://doi.org/10.1590/S0034-71672007000400012

[19] Dawalibi, N.W., Goulart, R.M.M. and Prearo,L.C. (2014) Factors Related to the Quality of Life of the Elderly in Programs for Senior Citizens. Ciência \& Saúde Coletiva, 19, 3505-3512. https://doi.org/10.1590/1413-81232014198.21242013

[20] Silva, M.V.M. and Tomaz, A.F. (2017) Quality of Life and Functional Capacity Analysis of Elderly People. Revista Tema, 18, 3-18. 